\title{
PEMBUATAN ALAT BANTU PENANGANAN ELEMEN TERAS REAKTOR RSG-GAS
}

\section{MANUFACTURE OF THE HANDLING TOOL OF RSG-GAS REACTOR CORE ELEMENT}

\author{
Pardi $^{1}$, Herdi Affrizal ${ }^{2}$, Camelia ${ }^{3}$ \\ 1.2.3PRSG-BATAN, Kawasan Puspiptek Gd.30, Serpong, 15310 \\ e-mail: pardi@batan.go.id.
}

Diterima: 24 Oktober 2019, diperbaiki: 31 Oktober 2019, disetujui : 4 Nopember 2019

\begin{abstract}
ABSTRAK
PEMBUATAN ALAT BANTU PENANGANAN ELEMEN TERAS REAKTOR RSG-GAS. Alat bantu penanganan elemen teras baru dibutuhkan dalam pembentukan teras kerja reaktor $R S G$ GAS agar faktor keselamatan tetap terpenuhi. Alat bantu penanganan elemen teras yang lama sudah mengalami penuaan (aging) dan rusak, sehingga perlu direvitalisasi serta modifikasi lubang udara. Modifikasi lubang udara pada alat bantu baru perlu dilakukan, karena alat penanganan elemen teras yang lama jumlahnya sedikit, sehingga ketika proses loading/unloading pembentukan teras membuat handling tool melayang dan sulit untuk diarahkan. Metoda pembuatan alat bantu penanganan elemen teras baru ini mengacu pada metoda dan spesifikasi peralatan penanganan elemen teras lama seperti komponen, jenis material maupun ukurannya. Material yang digunakan untuk alat penanganan elemen teras adalah pipa Al 6063 diameter 25,4 × $1 \mathrm{~mm}$ sebagai pipa dalam yang berfungsi untuk pengunci dan pipa Al 6063 diameter $45 \times 2$ mm merupakan pipa luar yang berfungsi sebagai pemegang dan pemindah. Tahapan pembuatan alat penanganan elemen teras multiguna dimulai dari identifikasi masalah, perancangan dan pembuatan gambar teknis, fabrikasi, instalasi dan uji fungsi. Dari hasil uji fungsi yang dilakukan diperoleh hasil bahwa alat ini dapat berfungsi dengan baik, serta efektif dalam pengoperasiannya.
\end{abstract}

Kata kunci : Alat penanganan elemen teras, pembuatan dan pengujian

\begin{abstract}
MANUFACTURE OF THE HANDLING TOOL OF RSG-GAS REACTOR CORE ELEMENT.The new handling tool of RSG-GAS core element needs to be manufactured to fulfill the safety aspects of the reactor operation. The recently used handling tool of reactor core element is aging by the time, causing some damage that needs to be revitalized and modified with the new air holes. The existing handling tool only has a few air holes that made the handling tool float in the water which made it difficult to be directed on the process of loading and unloading. By the fact, the personnel of the reactor makes the new modification by adding the new air holes to solve the recent issue. The method of making process of the handling tool is referring to the method and specification of the existing handling tool like component, kinds of material and the measurement. The material used in the process is an Al 6063 pipe with a diameter of 25,4 41 $\mathrm{mm}$ which functioned as the inner locking pipe, and an outer Al 6063 pipe with a diameter of 45 $x 2 \mathrm{~mm}$ which functioned as the handling. The making process of the new handling tool begins with the identification of the issue, design of the technical drawings, fabrication, installation and functional test. The result of the functional test shows that this handling tool performed an excellent function and operationally effective.
\end{abstract}

Keywords: handling tool, manufacture, functional test 


\section{PENDAHULUAN}

\section{Peaktor Serba Guna-G.A.} Siwabessy (RSG-GAS) merupakan reaktor penelitian yang berfungsi untuk penelitian, produksi radioisotop dan uji bahan, sehingga disebut reaktor serba guna. RSG-GAS menggunakan bahan bakar silisida $\mathrm{U}_{3} \mathrm{Si}_{2}-\mathrm{Al}$ dengan pengayaan uranium rendah yaitu \pm 19,75\%. Teras RSG-GAS menghasilkan daya termal nominal $30 \mathrm{MW}$ dan fluks neutron maksimum sebesar $2,52 \times 10^{-14}$ $\mathrm{n} / \mathrm{cm}^{2}$.s. Konfigurasi teras tersusun atas kisi $10 \times 10$ berisi 40 elemen bakar dan 8 batang kendali. ${ }^{[1-2]}$

RSG-GAS beroperasi rutin selama 10 operasi/siklus dengan setiap operasi selama 5 hari/operasi pada daya $15 \mathrm{MW}$ atau setara dengan energi yang dibangkitkan sebesar 650 MWD. Setelah energi tersebut tercapai maka perlu dilakukan proses pembentukan teras kerja baru. Pembentukan teras kerja baru reaktor RSG-GAS adalah pelaksanaan manajemen bahan bakar yang berkaitan dengan pemasukan dan pengeluaran bahan bakar di dalam teras reaktor dan dilaksanakan sesuai dengan surat Perintah Pemindahan Elemen Teras (PPET). Setiap kali pembentukan teras kerja baru selalu mengacu pada hasil perhitungan manajemen teras dengan menggunakan program BATAN-FUEL dan juga data parameter operasi teras setimbang reaktor RSG-GAS sebelumnya, seperti energi yang sudah dibangkitkan selama satu siklus operasi. Proses tersebut dilakukan dengan mengganti 5 Elemen Bakar dan 1 Elemen Kontrol. ${ }^{[3]}$

Pada proses penggantian bahan bakar membutuhkan alat bantu untuk memindahkan elemen bakar yang disebut alat bantu penanganan elemen teras (handling tool). Alat bantu penanganan elemen teras ini digunakan untuk membantu memasukkan bahan bakar baru, memindahkan bahan bakar bekas ke tempat penyimpanan sementara (spent fuel) dan menggeser posisi bahan bakar. Pada saat ini, beberapa peralatan seperti alat bantu penanganan element teras sudah mengalami penuaan (aging) dan bahkan ada yang sudah rusak. Alat bantu penanganan elemen teras yang digunakan saat ini didesain dan dibuat oleh Kusno dkk (2002). ${ }^{[4]}$

Hasil dari evaluasi keselamatan dalam pembentukan teras kerja baru dan revitalisasi peralatan penanganan elemen teras, maka perlu dilakukan modifikasi dan pembuatan alat penanganan elemen teras yang baru dengan standar keselamatan yang tinggi dan efisien dalam hal penggunaannya. Hal ini bertujuan agar dalam melakukan pemindahan elemen teras reaktor dapat terlaksana dengan aman dan selamat, sehingga tercapainya "Zero Accident" secara berkelanjutan.

Tujuan pembuatan alat bantu penanganan elemen teras (handling tool) adalah sebagai alat bantu pada proses penanganan elemen teras yang berfungsi untuk memegang dan sekaligus untuk memindahkan elemen teras dari dan ke teras reaktor, rak intermediate, dan rak jembatan geser yang berada di kolam reaktor. Proses pembuatan alat penanganan elemen teras ini, melalui beberapa tahapan seperti identifikasi masalah, perancangan dan pembuatan gambar teknis, fabrikasi, instalasi dan pengujian yang mempertimbangkan faktor keselamatan dan keamanan dalam pelaksanaannya..$^{[5-6]}$ Sehingga alat ini diharapkan dapat mengurangi faktor kesalahan dalam kegiatan penanganan elemen teras. 


\section{DESKRIPSI}

Alat penanganan elemen teras, lebih tepatnya disebut dengan handling tool, alat penanganan elemen teras (handling tool) ini dapat didefinisikan sebagai alat bantu proses penanganan elemen teras yang berfungsi untuk memegang dan memindahkan elemen teras saat pelaksanaan pembentukan teras kerja baru. Secara umum alat ini tersusun dari dua bagian pipa utama. Pertama, pipa bagian luar dengan pengait, berfungsi sebagai pengait dan juga untuk memindahkan elemen teras. Kedua, pipa bagian dalam yang dapat berfungsi sebagai pengunci elemen teras.

\section{METODOLOGI}

Pembuatan alat bantu penanganan elemen teras (handling tool) ini dilakukan dengan 5 tahapan, diantaranya yaitu: identifikasi masalah, perancangan dan pembuatan gambar teknis, fabrikasi, instalasi, dan uji fungsi secara langsung menggunakan elemen bakar reaktor RSG-GAS. Dalam pelaksanaan uji fungsi menggunakan prosedur penanganan elemen teras yang sudah ada. ${ }^{[7]}$

\subsection{IDENTIFIKASI MASALAH}

Kegiatan pembentukan teras kerja baru adalah proses mengganti 5 buah Elemen Bakar Standar dan 1 buah Elemen Bakar Kendali, elemen teras yang lain dilakukan reposisi sesuai dengan prosedur dan perintah pemindahan elemen teras yang berlaku. Proses loading adalah proses memasukkan Elemen Bakar Standar/ Kendali yang baru ke posisi Teras Reaktor, sedangkan proses unloading adalah proses mengeluarkan Elemen Bakar Standar/ Kendali yang sudah mencapai fraksi bakar (burn-up) ke posisi bahan bakar bekas (spent fuel).

Proses loading/unloading elemen bakar saat ini menggunakan handling tool yang memiliki Panjang \pm 13 meter diatas teras reaktor dengan 2 pengunci, pertama berada di Top Handle (diatas) dan kedua berada di posisi Middle Handle (ditengah). Pengunci Top Handle digunakan untuk mengunci/melepas elemen bakar pada posisi teras reaktor, sedangkan Middle Handle digunakan untuk mengunci/melepas elemen bakar pada posisi intermediate maupun jembatan geser. Pada saat akan memasukkan elemen bakar baru, maka perlu mengganti handling tool yang memiliki panjang \pm 6 meter dan memiliki pengunci di Bottom Handle (dibawah). Selain itu, lubang udara pada handling tool saat ini cukup sedikit sehingga ketika proses loading/unloading membuat handling tool melayang dan sulit untuk diarahkan.

Untuk mengatasi masalah ini dilakukan sebuah rancang bangun alat bantu penanganan elemen teras (handling tool) yang dapat digunakan untuk proses loading/unloading elemen bakar di segala posisi pada teras reaktor tanpa melakukan penggantian handling tool. Sehingga proses loading/unloading elemen bakar dapat berjalan lebih efektif dan efisien. ${ }^{[8]}$.

\subsection{PERANCANGAN DAN PEMBUAT- AN GAMBAR TEKNIS}

Untuk memperoleh alat bantu penanganan elemen teras (handling tool) yang dapat digunakan dengan baik sesuai spesifikasinya, diperlukan data penggunaan alat secara menyeluruh. Alat bantu penanganan elemen teras hanya dapat digunakan untuk beban kerja dan jenis elemen teras tertentu seperti: elemen bakar, elemen dummy, dummy elemen bakar, stringer dan plug. Data tersebut diperlukan untuk pembuatan gambar kerja. Gambar kerja merupakan pegangan yang harus ditaati saat pembuatan suatu alat, oleh sebab itu gambar dibuat sesederhana mungkin 
seperti yang ditujukan pada Gambar 1 berikut :

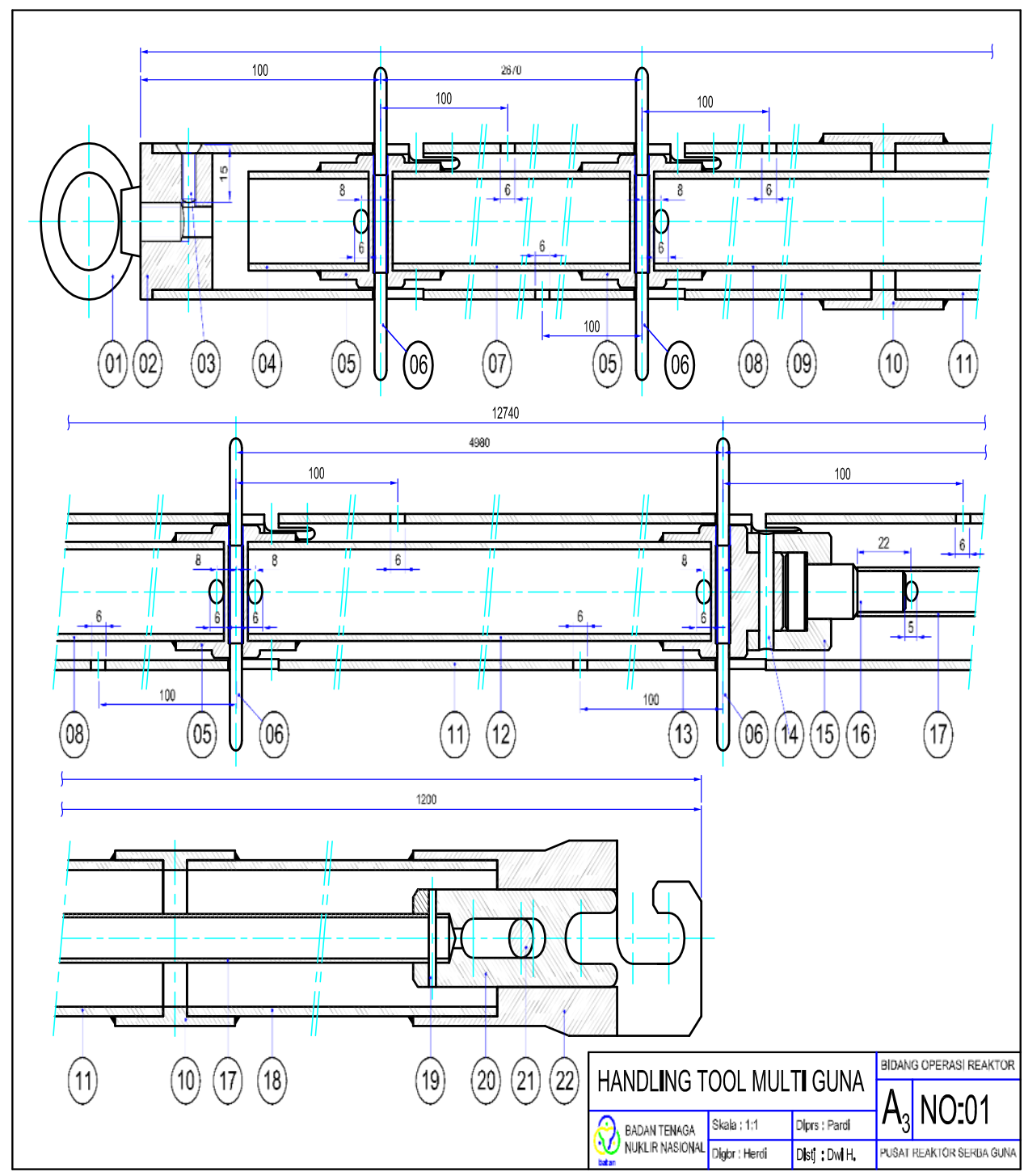

Gambar 1. Gambar Teknis Alat Bantu Penanganan Elemen Teras (Handling Tool)

Pemilihan material mengacu pada pengaruh lingkungan kerja tidak alat yang sudah ada, hal ini dimaksudkan membuat alat tersebut korosi ${ }^{[6]}$. Material agar bentuk, jenis dan fungsi alat sesuai yang digunakan seperti pada Tabel 1 dengan karakteristik beban serta berikut ini : 
Tabel 1. Daftar Material yang Digunakan

\begin{tabular}{clccc}
\hline No & \multicolumn{1}{c}{ Nama } & Ukuran & Material & Jumlah \\
\hline 1 & Pengait & - & Al 6063 & 1 \\
\hline 2 & Pipa bagian luar & $\varnothing 45 \times 3$ & Al 6063 & 2 \\
\hline 3 & Pipa bagian dalam & $\varnothing 20 \times 3$ & Al 6063 & 3 \\
\hline 4 & Pipa bagian dalam & $\varnothing 12 \times 2$ & Al 6063 & 1 \\
\hline 5 & Tutup atas & - & Al 6063 & 1 \\
\hline 6 & Garpu pengunci & - & Al 6063 & 1 \\
\hline 7 & Rumah tuas pengunci & - & Al 6063 & 4 \\
\hline 8 & Tuas pengunci & $\varnothing 6 \times 80$ & Al 6063 & 4 \\
\hline 9 & Pena & $\varnothing 6 \times 50$ & Al 6063 & 1 \\
\hline 10 & Pena & $\varnothing 6 \times 35$ & Al 6063 & 1 \\
\hline 11 & Pena & $\varnothing 6 \times 30$ & Al 6063 & 1 \\
\hline 12 & Baut mata & M10 & SS 304 & 1 \\
\hline
\end{tabular}

\subsection{FABRIKASI}

Alat bantu penanganan elemen teras ini dibuat dari bahan aluminium (Al 6063) dengan mengacu pada gambar kerja yang sudah ada, seperti yang terlihat pada Gambar 1 diatas, secara rinci bagian per bagian mekanik untuk satu unit dibagi dalam 18 komponen. Proses pembuatan alat bantu penanganan elemen teras dilakukan satu demi satu secara berurutan dari setiap komponen, seperti urutan komponen dalam Tabel 2 berikut ini:

Tabel.2. Daftar Komponen dan Material yang Digunakan

\begin{tabular}{|c|c|c|c|c|}
\hline No & Komponen & Ukuran $(\mathrm{mm})$ & Material & Jumlah \\
\hline 1 & Baut mata (eye bolt) & M10 & SS 304 & 1 \\
\hline 2 & Tutup atas & - & SS 304 & 1 \\
\hline 3 & Sekrup & $\mathrm{M} 6 \times 15$ & SS 304 & 3 \\
\hline 4 & Rumah tuas pengunci atas & - & Al 6063 & 1 \\
\hline 5 & Tuas pengunci & $\varnothing 6 \times 80$ & SS 304 & 4 \\
\hline 6 & Pipa bagian luar & $\varnothing 40 \times 2$ & Al 6063 & 2 \\
\hline 7 & Pipa bagian dalam I & $\varnothing 25,4 \times 1$ & Al 6063 & 3 \\
\hline 8 & Rumah tuas pengunci tengah & - & Al 6063 & 2 \\
\hline 9 & Penyambung pipa luar & - & Al 6063 & 2 \\
\hline 10 & Rumah tuas pengunci bawah & - & Al 6063 & 1 \\
\hline 11 & Pena rumah putar & $\varnothing 6 \times 35$ & SS 304 & 1 \\
\hline 12 & Rumah kepala putar & - & Al 6063 & 1 \\
\hline 13 & Kepala putar & - & Al 6063 & 1 \\
\hline 14 & Pipa bagian dalam II & $\varnothing 12 \times 1$ & Al 6063 & 1 \\
\hline 15 & Pena garpu pengunci & $\varnothing 3 \times 24$ & SS 304 & 1 \\
\hline 16 & $\begin{array}{lll}\begin{array}{l}\text { Pena penahan garpu } \\
\text { pengunci }\end{array} & \\
\end{array}$ & $\varnothing 9,5 \times 42$ & SS 304 & 1 \\
\hline 17 & Garpu pengunci & - & Al 6063 & 1 \\
\hline 18 & Pengait & - & Al 6063 & 1 \\
\hline
\end{tabular}

Dari data Tabel diatas, semua komponen adalah bagian - bagian mekanik untuk satu unit alat penanganan elemen teras yang dibuat dan dikerjakan di bengkel 
dan oleh staf PRSG berdasarkan pada gambar mekaniknya. Mesin perkakas yang digunakan untuk fabrikasi adalah mesin gergaji, mesin bubut, mesin frais, mesin bor, mesin las dan mesin perkakas dan lainnya. Proses pembuatan alat bantu penanganan elemen teras (handling tool) seperti ditunjukkan pada Gambar 2 berikut:

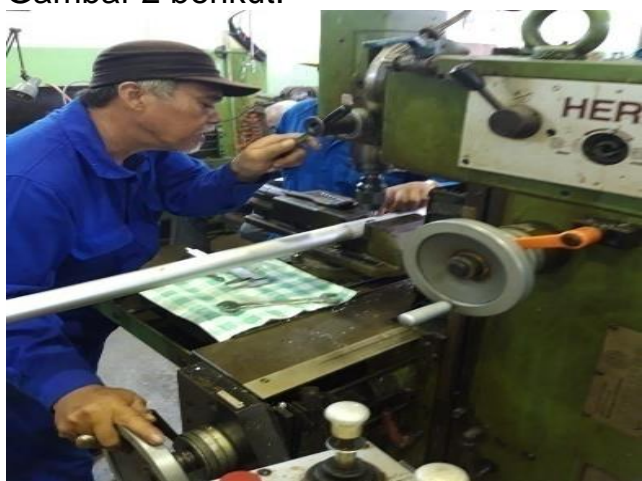

Gambar 2. Proses pembuatan Alat Bantu Penanganan Elemen Teras (Handling Tool)

\subsection{INSTALASI}

Setelah semua komponen mekanik selesai dibuat, maka bagian satu dengan bagian lainnya disambungkan (rangkai) sesuai gambar, menggunakan alat las dan juga secara langsung pakai skrup. Sehingga semua bagian dapat menjadi suatu alat bantu penanganan elemen teras (handling tool) yang utuh dan dapat digunakan sesuai perencanaan. Proses penyambungan (instalasi) alat bantu penanganan elemen teras (handling tool) dapat ditunjukkan pada Gambar 3.

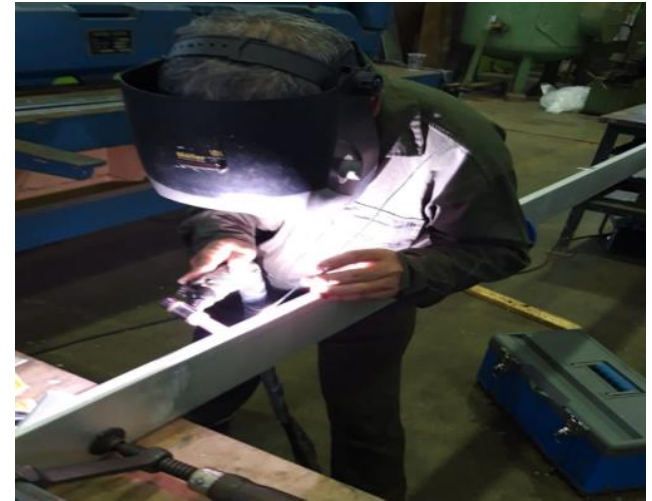

Gambar 3. Proses penyambungan Alat Bantu Penanganan Elemen Teras (Handling Tool)

Gambar 4. Alat bantu penanganan elemen teras dibungkus menggunakan plastik untuk tujuan keselamatan saat pemindahan serta mengurangi kotoran debu saat penyimpanan. Sebelum dibungkus alat bantu penanganan elemen teras tersebut dibersihkan dengan air, kemudian alkohol/aseton agar benarbenar bersih dari kotoran (sisa scrap) yang menempel pada alat pasca fabrikasi dan penyambungan menggunakan las.

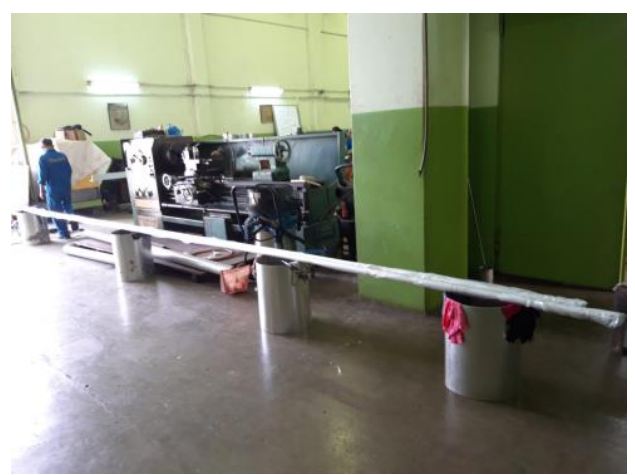

Gambar 4. Alat bantu penanganan elemen teras (Handling Tool)

\subsection{UJI FUNGSI}

Alat bantu Penanganan elemen teras (Handling Tool) dirancang untuk memindahkan elemen teras dari dan ke teras reaktor, rak intermediate, dan rak jembatan geser yang berada di kolam 
reaktor. Uji fungsi dilakukan mulai dari memindahkan elemen bakar yang sudah mencapai fraksi bakar (burn up) 56,6\% dari teras reaktor ke rak bahan bakar bekas (spent fuel) dan memasukkan elemen bakar baru (fresh fuel) ke dalam teras reaktor untuk membentuk teras kerja baru.

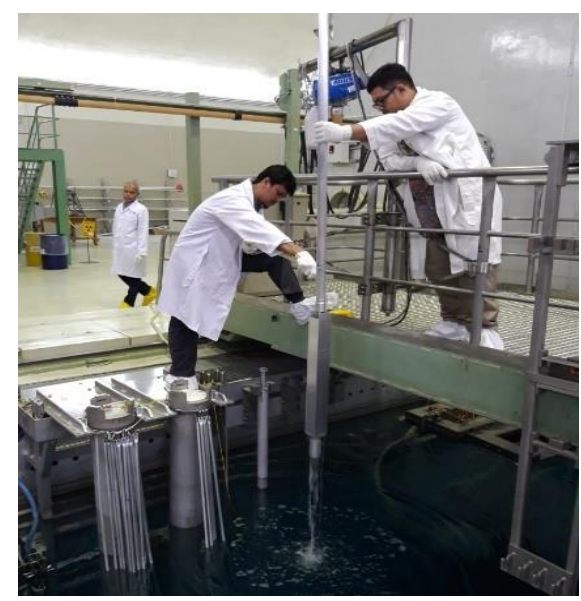

Gambar 5. Proses uji coba alat bantu penanganan elemen teras (handling tool) dengan bahan bakar baru di spent fuel

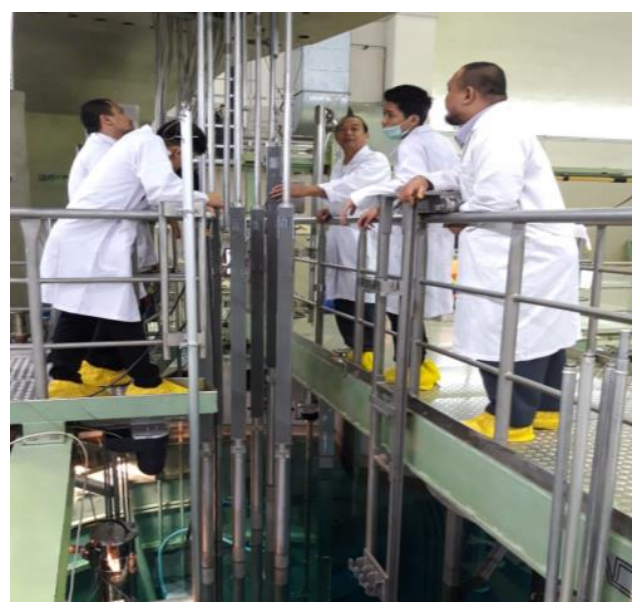

Gambar 6. Proses uji coba alat bantu penanganan elemen teras (Handling Tool) di posisi teras reaktor
Pada Gambar 5, adalah proses pengujian yang dilakukan terhadap bahan bakar segar (fresh fuel) dengan mengaitkan pada alat bantu penanganan elemen teras (Handling Tool) kemudian dikunci. Sebelum bahan bakar segar (fresh fuel) dimasukkan ke teras reaktor perlu dilakukan pembilasan menggunakan air bebas mineral di kolam spent fuel agar kotoran yang menempel selama proses penyimpanan bahan bakar di gudang penyimpanan bahan bakar segar tidak terbawa ke teras reaktor. ${ }^{(8)}$ Kemudian jembatan geser diposisikan di atas teras reaktor untuk memindahkan bahan bakar segar (fresh fuel) ke dalam teras reaktor (posisi I). Ada lima bahan bakar segar yang dimasukan ke dalam teras reaktor untuk menggantikan lima bahan bakar yang fraksi bakar (burn up) sudah mencapai 56,6\%.

Gambar 6, adalah proses pengujian alat bantu penanganan elemen teras (Handling Tool) saat pembentukan Teras-99. Sistem manajemen pembentukan teras reaktor menganut Pola 5/1 (5 bahan bakar standar FE dan 1 bahan bakar kontrol CE), berdasarkan perhitungan di akhir siklus operasi ada 5 bahan bakar standar dan 1 bahan bakar kontrol yang fraksi bakar (burn-up) telah mencapai 56,6\% dan harus dikeluarkan dari teras reaktor dan disimpan di rak penyimpanan bahan bakar bekas di kolam spent fuel (posisi IV). Kemudian diganti dengan bahan bakar segar (fresh fuel) yang fraksi bakar (burn-up) masih 0\% (5 bahan bakar standar dan 1 bahan bakar kontrol), dimasukan secara bertahap ke teras reaktor. Setiap langkah pemindahan bahan bakar dari dan keluar teras reaktor berdasarkan pada langkah yang tertulis dalam Perintah Pemindahan Elemen Teras (PPET) dan disaksikan oleh satu orang staf Subbid. Keselamatan Operasi Reaktor guna memperoleh keyakinan bahwa pelaksanaan 
loading-unloading bahan bakar oleh tersebut. ${ }^{(9-10)}$ Langkah kerja pelaksanaan operator reaktor telah sesuai dengan pembentukan teras 99 dapat dilihat pada langkah kerja yang ada dalam PPET Tabel 3.

Tabel 3. Daftar uji fungsi alat bantu penanganan elemen teras (handling tool) dengan elemen bakar Teras 99

\begin{tabular}{|c|c|c|c|c|c|c|c|c|c|c|}
\hline \multirow{3}{*}{ NO } & \multirow{3}{*}{ JENIS ELEMEN } & \multicolumn{8}{|c|}{ PEMINDAHAN } & \multirow{3}{*}{ HASIL } \\
\hline & & \multicolumn{4}{|c|}{ DARI POSISI } & \multicolumn{4}{|c|}{ KE POSISI } & \\
\hline & & 1 & II & III & IV & $\mathrm{I}$ & II & III & IV & \\
\hline 1 & FE-RI-588 & G-8 & - & - & - & - & - & $a$ & $E-6$ & OK \\
\hline 2 & FE-RI-581 & $B-8$ & - & - & - & - & - & $b$ & $1-5$ & OK \\
\hline 3 & FE-RI-586 & $B-5$ & - & - & - & - & - & c & $\mathrm{C}-6$ & OK \\
\hline 4 & FE-RI-582 & D-8 & - & - & - & - & - & d & B-6 & OK \\
\hline 5 & FE-RI-587 & $\mathrm{F}-6$ & - & - & - & - & - & e & D-6 & OK \\
\hline 6 & CERI-585 + 12 & B-7 & - & - & - & - & - & $f$ & $\mathrm{~K}-10$ & OK \\
\hline 7 & CERI-635 + 12 & \multicolumn{4}{|c|}{ BARU } & C-8 & - & - & - & OK \\
\hline 8 & FE-RI-631 & \multicolumn{4}{|c|}{ BARU } & $\mathrm{H}-4$ & - & - & - & OK \\
\hline 9 & FE-RI-632 & \multicolumn{4}{|c|}{ BARU } & $A-9$ & - & - & - & OK \\
\hline 10 & FE-RI-633 & \multicolumn{4}{|c|}{ BARU } & C-3 & - & - & - & OK \\
\hline 11 & FE-RI-634 & \multicolumn{4}{|c|}{ BARU } & $F-3$ & - & - & - & OK \\
\hline 12 & FE-RI-636 & \multicolumn{4}{|c|}{ BARU } & $\mathrm{H}-9$ & - & - & - & OK \\
\hline
\end{tabular}

Dari data Tabel 3. Pemindahan lima bahan bakar yang fraksi bakar (burn-up) telah mencapai $56,6 \%$ (FE-RI-588, FERI-581, FE-RI-586, FE-RI-582, FE-RI587) dari teras reaktor posisi I (G-8, B-8, B-5, D-8, F-6) dipindah ke posisi III Rak Jembatan Geser (a, b, c, d, e) kemudian disimpan di Rak Spent Fuel posisi IV (E6, I-5, C-6, B-6, D-6). Masuk lima bahan bakar baru (FE-RI-631, FE-RI-632, FERI-633, FE-RI-634, FE-RI-636) ke posisi I teras reaktor $(\mathrm{H}-4, \mathrm{~A}-9, \mathrm{C}-3, \mathrm{~F}-3, \mathrm{H}-9)$. Kemudian kontrol elemen CE-RI-585 disimpan di Rak Spent Fuel posisi IV K10 dan diganti dengan kontrol elemen CE-RI-635 baru masuk ke posisi I teras C-8. Adapun maksud dalam Tabel 3. Hasil OK adalah bahwa pekerjaan loading-unloading bahan bakar telah sesuai dengan langkah yang ada dalam PPET.

\section{PEMBAHASAN}

Pelaksanaan Rancang Bangun alat bantu penanganan elemen teras (handling tool) di Reaktor RSG-GAS dilakukan dalam beberapa tahap meliputi: identifikasi masalah, perancangan dan pembuatan gambar teknis, fabrikasi, instalasi dan uji fungsi.

Pada tahap pertama dilakukan adalah mengidentifikasi permasalahan yang ada pada alat bantu penanganan elemen teras (handling tool). Permasalahan-permasalahan tersebut diperoleh dari hasil analisis di lapangan dan diskusi terhadap personil yang menggunakan alat tersebut. Hasilnya adalah alat bantu penanganan elemen teras (handling tool) yang saat ini digunakan kurang efektif dan efisien karena harus mengganti alat bantu penanganan elemen teras (handling tool) untuk pekerjaan yang sama. Kedua, udara terjebak di dalam pipa alat bantu penanganan elemen teras (handling tool) dan aliran air di dalam pipa alat bantu penanganan elemen teras (handling tool) terhambat. Sehingga pada saat loading/unloading, alat bantu penanganan elemen teras (handling tool) sulit untuk diarahkan akibat dari tekanan udara yang terjebak. 
Pada proses perancangan dan pembuatan gambar teknis, dilakukan diskusi untuk mengatasi permasalahan tersebut. Hasilnya adalah melakukan modifikasi alat bantu penanganan elemen teras (handling tool) dengan menambahkan pengunci di setiap posisi loading/ unloading mulai dari teras reaktor, rak intermediate, rak jembatan geser dan rak bahan bakar bekas (spent fuel). Sebelumnya menggunakan beberapa handling tool untuk proses loading/ unloading, sekarang cukup menggunakan alat bantu penanganan elemen teras (handling tool) yang baru. Selain itu, dilakukan modifikasi lubang udara yang terdapat pada alat bantu penanganan elemen teras (handling tool). Diharapkan dengan adanya lubang-lubang tersebut tidak terdapat udara yang terjebak dan aliran air lebih lancar, sehingga alat bantu penanganan elemen teras (handling tool) lebih mudah diarahkan.

Pada tahap berikutnya, bahan yang digunakan untuk pembuatan alat bantu penanganan elemen teras (handling tool) harus memperhatikan standar bahan yang diijinkan untuk instalasi reaktor nuklir. Selain itu, untuk mengurangi tingkat korosi baik pada elemen bakar dan handling tool maka bahan yang digunakan harus sejenis dengan elemen bakar. Sehingga bahan yang digunakan adalah Aluminium 6063 (Al 6063) dan Stainless Steel (SS 304).

Proses pembuatan alat bantu penanganan elemen teras (handling tool) harus dibuat urutan prioritas pembuatan, mulai dari pemengan dan pemindah hingga ke pengunci elemen bakar. Material yang digunakan untuk alat penanganan elemen teras multiguna ini adalah pipa Al 6063 diameter 25,4 x 1 $\mathrm{mm}$ sebagai pipa dalam yang berfungsi untuk pengunci dan pipa Al 6063 diameter $45 \times 2 \mathrm{~mm}$ merupakan pipa luar yang berfungsi sebagai pemegang dan pemindah.

Pada proses instalasi tidak didapatkan kesulitan, karena semua komponen utama dan pendukung telah dibuat sesuai dengan gambar teknis dan telah dilakukan pengecekan sebelum nya. Sehingga pada saat pemasangan tidak bias, tepat dan sesuai yang diharapkan.

Setelah alat bantu penanganan elemen teras (handling tool) selesai, sebelum memasukan ke dalam kolam reaktor perlu dibersihkan dari kotoran, debu maupun sisa scrap yang masih menempel dengan cairan aseton sampai benar-benar bersih. Setelah semua sisi bersih, selanjutnya alat bantu penanganan elemen teras (handling tool) tersebut dibawa menuju kolam reaktor dengan bantuan crane untuk dilakukan uji fungsi.

Pada saat uji fungsi, alat bantu penanganan elemen teras (handling tool) dapat digunakan untuk pengambilan/ penempatan elemen teras dari dan ke teras reaktor, rak intermediate, rak jembatan geser dan rak bahan bakar bekas (spent fuel). Kemudian untuk pengambilan elemen bakar sudah cukup mudah, karena sudah ditambah lubang udara pada bagian bawah agar aliran air menjadi lancar dan tidak ada udara yang terjebak. Sedangkan untuk pengunci handling tool sudah lancar dan gampang untuk digunakan. Alat bantu penanganan elemen teras (handling tool) telah terpasang dengan baik dan siap digunakan untuk proses loading/ unloading elemen bakar pembentukan teras kerja baru.

\section{KESIMPULAN}

Pembuatan alat bantu penanganan elemen teras (handling tool) reaktor RSG-GAS telah selesai dilaksanakan dan digunakan. Hasil uji fungsi alat bantu tersebut lebih efektif dan efisien sehingga 
sangat membantu proses loading/ unloading elemen bakar.

\section{UCAPAN TERIMA KASIH}

Terima kasih sebesar-besarnya kepada bapak Dwi Haryanto, Warsono, Arif Hidayat dkk yang telah banyak membantu dan menyelesaikan Pembuatan alat bantu penanganan elemen teras (handling too).

\section{DAFTAR PUSTAKA}

[1] Laporan Analisis Keselamatan (LAK) RSG-GAS Rev.10.1. PRSG BATAN. 2011.

[2] Iman K. "Keselamatan Reaktor Nuklir". Batan Press. 2017.

[3] Mochamad Imron, Ariyawan Sunardi. "Perhitungan Burn Up Bahan Bakar Reaktor RSG-GAS Menggunakan Paket Program BATAN-FUEL", Prosiding Seminar Nasional Teknologi dan Aplikasi Reaktor Nuklir - PRSG. 2012.

[4] Kusno, Harsono dkk. "Pembuatan dan Uji Fungsi Alat Penangan Elemen Teras Multiguna di RSGGAS", Prosiding Seminar Hasil Penelitian P2TRR. 2002.
[5] Sunarko dkk. "Rancang Bangun Handling Tool Loading/Unloading Fasilitas Silikon Doping", Seminar Pendayagunaan Teknologi Nuklir BATAN. 2017.

[6] Asnul Sukmawan, Kawkab Mustafa "Pembuatan Tabung Iradiasi Topaz Incore" Prosiding Seminar Nasional Teknologi dan Aplikasi Reaktor Nuklir - PRSG. 2014.

[7] Anhar R. A., Mulya J. "Keselamatan Reaktor Nuklir: Kecelakaan Dasar Desain dan Kecelakaan Parah". Batan Press. 2018.

[8] BAPETEN, "Peraturan Kepala Badan Pengawas Tenaga Nuklir Nasional No. 2 Tahun 2014 tentang Manajemen Teras serta Penanganan dan Penyimpanan Bahan Bakar Nuklir pada Reaktor Non Daya," 2014.

[9] Standar Operasional Prosedur, "Pembentukan Teras Kerja Baru," nomor: SOP 020.002/RN 00 01/RSG 2. 2016.

[10] Perintah Pemindahan Elemen Teras, "Pembentukan Teras 99", nomor: RSG.OR.PPET 01/99/2019. 2019. 